\title{
Education Decentralisation in Malawi: Legitimate but Incomplete Masked in Dilemmas of Leadership Roles and Responsibilities
}

\author{
Noel Kufaine \\ University of Malawi, Technical Education Department, Private Bag 303, Chichiri, Blantyre 3. Malawi \\ Noel.kufaine@yahoo.com.or nkufaine@poly.ac.mw
}

Oliver Mtapuri

University of Limpopo, Turfloop Graduate School of Leadership, P.O. Box. 759, Fauna Park, 0787, South Africa.

Email: simbaomtapuri@yahoo.com, oliver.mtapuri@ul.ac.za

\section{Doi:10.5901/mjss.2014.v5n23p764}

\section{Abstract}

Since the advent of multiparty democracy in Malawi, activities have been planned in line with the concept of democracy. One of the activities being undertaken in pursuit of democracy is decentralisation with a twofold purpose, namely, to improve effectiveness in service delivery and community participation. Decentralisation is being pioneered by the Ministry of Local Government and Rural Development, and then relayed to other government departments. Under the circumstances, the Department of Education was also decentralized. This article is part of the large study which was aimed at understanding the experience of decentralising education, considering the complexity of the sector. It is based on a qualitative study in Malawi and used the in-depth interviewing technique to collect data. A grounded theory approach was used to analyse them. The study revealed that decentralisation as a whole enhances democracy and community participation in social and rural development. However, other departments were just directed to decentralise to make decentralisation a national activity. The Education department has not completely decentralised because it was implemented by adopting the local government structure which operates and stops at the district level and has proved to be difficult in the sector. Hence, the article, concludes that while the decentralisation of education is critical and is also a valid initiative for a country like Malawi, it is not clear how education effectiveness will be reached. The article argues that the process of decentralization in Malawi is incomplete because it has not been decentralised to the school level. The article recommends that different departments and stages in the decentralisation process need to be regarded as distinct for effective planning and execution of education decentralization. This necessitates the need for concerted efforts at advocacy regarding this matter. The article also argues that the allocation and provision of appropriate resources and training is a long-term and ongoing process devoid of short cuts.

Keywords; decentralisation, democracy, participation, community, development

\section{Introduction}

The Government of Malawi embarked on a decentralisation program through the Ministry of Local Government and Rural Development (Local Government Act, 1998: 1). The primary objectives of the program are to improve service delivery, enhance participatory democracy and good governance (Local Government Act, 1998: 2). In Malawi, decentralisation involved central government departments transferring responsibility and authority to the district assembly through the Ministry of Local Government and Rural Development. Departments which are decentralized are accountable to the district assembly and the responsibility of the leadership is to look after the affairs of their departments in liaison with the district assembly committee responsible for their particular department and answerable to the district commissioner.

The education system in Malawi is managed through an education central office which has six education divisional offices which are responsible for the running of secondary education, thirty-three education district offices, which are responsible for running primary school education in the district, three-hundred and seventeen education zones, which are responsible for primary school monitoring and supervision and schools, which are responsible for teaching and learning.

The district education office has a district education manager, who serves as overall district education administrator; a district education desk officer who is responsible for the technical administrative issues in the district education office. There are three sub-divisions in the district education office: human resources with an officer responsible for personnel administration; finance with a principal accountant responsible for finance and senior education advisor responsible for the support, monitoring and supervision of education in schools. Under the district education 
office, there are education zones which are headed by a primary education advisor and primary schools headed by a head teacher. In the Ministry of Education, Science and Technology headquarters there are district education managers, primary school advisors and head teachers who all have some formal authority by virtue of their positions.

The government departments which are purported to have been decentralised are the departments of health and population, education, science and technology, trade and private sector development, water and irrigation, agriculture, gender, child welfare and community services and natural resources and environmental affairs (Kashoti, 2007). These departments are different in many aspects, therefore, merely directing them to decentralise may create a myriad of problems especially during execution. As such, evidence on the ground suggests that the decentralisation of the education department has been making slow progress due to barriers such as complexity of the activities in the department and lack of pre-requisite capabilities such as knowledge and experience to oversee the decentralisation process, and more importantly due to resistance to change (Rose, 2005).

Leadership is a major ingredient for education effectiveness and improvement because leaders are central to the decision making process and are key players in such transformation initiatives. Apart from mediating national policy to schools, leadership also sets and communicates visions for education in the district as well as building capacity in schools.

\section{Literature Review}

There is general consensus by different authors that decentralisation is a vague, slippery and complex concept to define because, as Bray (1985) argues, decentralisation covers a wide range of processes, activities and structures. It is generally recognised that decentralisation is considered a complex process and different authors found in extant literature have tried to define it. As such, Work (2002) defines decentralisation as the transfer of responsibility for planning, management and resource raising and allocation from the central government and its agencies to lower levels of government. This definition emanates from the understanding that decentralisation has a developmental agenda alongside the renewed global emphasis on governance and human development. Bray (1985) defines decentralisation as the transfer of decision making powers from higher levels in the official hierarchy to lower ones of the administrative system. Lane and Murray (1985) see decentralisation as re-assigning responsibility and corresponding decision authority for specific functions from higher to lower levels of government and organizational units. For McGinn and Welsh (1999) decentralisation is a shift in the location of those who govern, a transfer of authority from those in one location or level of organisation to those in another level. Lane and Murray (1985) and McGinn and Welsh (1999) argue that decentralisation is a continuation of what was being done by somebody at a higher level, but now being done by somebody at a lower level. Thus, the basic definition of decentralisation may be the transfer of decision making authority, responsibility and tasks from the higher to a lower organisational level. However, the question remains: how low is lower level of the organisation structure?

The diversity in the definition of decentralisation emanates from the complexity of the variables which are used to define this phenomenon. Education decentralisation has many facets concerning changes in the way the education systems goes about making policies, generating revenue, spending funds, training teachers, designing curricula and managing local schools (Dyer and Rose 2005). Hence, the process involves many stakeholders, but according to Dyer and Rose (2005) (See also Davies et al., 2003; Chisinga, 2005), stakeholders rarely make a distinction between the different types of decentralisation and do not often appreciate the consequences associated with each type usually due to the sidelining of stakeholders in a participatory democracy. It is important therefore, to clarify the type of authority and responsibility to be devolved and at what level.

On one hand, Naidoo (2003) points out that decentralisation takes many forms, depending on the level of government to which decisions are devolved and the kind of decisions moved to those levels of government and the rationale behind it. On the other, Chimombo (2005) maintains that education decentralisation is complex because it has different meanings and refers to different types and reforms of decentralised education administration, management and government system with different policy aims and strategies. As such, with different forms and different characteristics, profound policy implications will be met and different levels of success will also be expected. This, somewhat, also suggests that most of the decentralisation initiatives are fraught with both constraints and opportunities as this article shall demonstrate. It depends upon policy makers in making decisions on the form and degree of decentralization to consider seriously the challenges which decentralisation as a process presents. The most important pre-conditions for the successful implementation of decentralisation are staff and leadership capacity; clear lines of accountability; commitment by government to transfer adequate resources to districts, a stable political system and the sequence of form of decentralisation to be implemented (Tordoff, 1994; Fullan, 2005; Geo-Jaja, 2006; Dyer and Rose, 2005; Falleti, 1999),. 
According to Tordoff (1994), decentralisation to districts means the tasks which were performed at the central office will be done by staff at district level which entails the concomitant need to deploy qualified personnel. The district capacity, and its leadership capacity in particular, is critical in developing and sustaining those district level conditions believed essential for successful implementation of decentralisation (Spillane, 2003). Leadership, in this context, is understood to be the exercise of authority and the making of decisions, as well as directing and coordinating tasks relevant to the institutional goals. This authority can be exercised at any level (Davidoff and Lazarus (2002) and in the school context, leaders have an important role to play in drawing people together and motivating them to take leaps into often more responsible positions.

This implies that having a clear rationale is one thing, and having the goals fulfilled is another essentially because there are many factors to take into account and Work (2002) also argues that decentralisation is not a 'one size fit all' process.

In this article, leadership may be better described as the authority and capacity of the Ministry and district team, to guide the education system in an agreed strategic and developmental direction. Hence, the leadership at the district education office has the obligation to make things happen between headquarters and schools. Anderson (2003: 4) points out that the district plays a role in interpreting and mediating schools' response to state policy. Massell (2000: 2) argues that the district office act as a gatekeeper for state policy and school requests as they have to relay the instructions from education head office to schools as well as coordinate and respond to various schools' needs. Apart from mediating state policy at schools, the district leadership also sets and communicates the visions for education in the district, building capacity of schools, teachers and learners, assisting schools with monitoring and reflecting on their progress as well as facilitating inter-school sharing (Anderson 2003: 3, Massell 2000: 2, Ayee 1997: 39, Spillane and Thompson, 1997: 199).

According to Massell (2000: 6), lack of coordination between central office leadership and district leadership creates tensions which often lead to the central office opting to operate directly with schools, bypassing the district. This usually happens when the central office is threatened with a loss of power and control. Donors also sometimes would want to go straight to schools, bypassing the district office (Ayee 1997: 52). This situation undermines the district leadership and its control on how schools operate and perform goals set by state, whether or not they have the necessary capacity to do so. Accountability is still required at all levels.

Accountability according to Anderson (2003: 10) is a tool for holding officials at all levels accountable for progress towards national goals. So Ministry headquarters and district offices should be held accountable. There is need to create what is called pressure and support (Fullan, 2005: 175) or rather, in this situation, a balance between support and pressure so that these support and pressure strategies result in more effective accountability with consequences. Therefore, the district office is the pivot for development in the district. This is achieved by planning, financing and infrastructure development, which is done by adapting existing standards and operating procedures (Ayee, 1997: 38). However, despite the introduction of decentralisation and institutional reforms, De Grauwe, et al (2005: 3) argue that the performance of local districts has not been responsive due to several challenges which they cannot address effectively such as: lack of pre-requisite capabilities like knowledge and experience to oversee the decentralisation process, and the situation to be answerable to two ministries. Anderson (2003: 7) points out that district leadership is also challenged to respond to disparities within themselves. There are high expectations from communities, which the district cannot easily achieve (Ayee, 1997: 53). Therefore, leadership capacity in the district can make or break the decentralization process in Malawi.

\section{Methodology}

This article attempts to provide a better understanding of the experience and expectations associated with the implementation of education decentralisation at district level. The study adopted a qualitative research approach whose purpose is to understand the social phenomena from the respondents and participants' perspective (Macmillan and Schumacher, 2006). The study adopted purposive sampling which uses the researcher's judgment as to which colleges are rich in the information to address the research questions of the study.

Individual in-depth interviews were conducted with 2 gate keepers, namely, the Director of Planning and the District Education Manager. Document analysis was also used to provide an opportunity for triangulation. Document analysis involves the reviewing and analysis of official documents that were useful in terms of the information and themes the research is investigating. The study used a semi-structured interview schedule in order to get an insight into the understanding of the concept of decentralisation from the respondents and how it is being implemented. 


\section{Results and Discussion}

According to reports, the introduction of decentralisation to different district assemblies was meant to improve service delivery, enhance participatory democracy as well as good governance. In this case district assemblies were encouraged to be independent and self-reliant. In order to achieve this, different departments in the district assemblies were to take active roles in fulfilling the new roles and responsibilities. This created some sort of confusion because of the differences in the characteristics of the departments and what they require to operate effectively. This article's ambition was to address the questions: how have district education offices functioned since decentralisation was instituted in 1998, and to what extent have their operations been affected in relation to achieving the expected goals of decentralisation?

The study revealed that, history of education in Malawi shows that education was started by the missionaries as a means of spreading the word of God. The government gradually took over the responsibility of running the schools. This development did not change the ownership of schools and religious agencies still have powers over what takes place in schools. Table 1 below shows that there are more schools owned by Religious groups than government schools. However, it should be noted that the current education decentralisation process has not included religious agencies as stakeholders, and because practically they are not involved in district development in general and education development in particular.

Table 1: Primary Schools according to Ownership (2006)

\begin{tabular}{|lcccc|} 
& Government & Religious & Private & Total \\
\hline School & 1904 & 3137 & 190 & $\mathbf{5 2 3 1}$ \\
\hline Classrooms & 12881 & 23954 & 1373 & $\mathbf{3 8 2 0 8}$ \\
\hline Teachers & 16077 & 25560 & 1560 & $\mathbf{4 3 1 9 7}$ \\
\hline \hline Learners & $\mathbf{1 1 5 4 4 3 9}$ & $\mathbf{2 0 8 8 0 4 4}$ & $\mathbf{3 8 2 3 1}$ & $\mathbf{3 2 8 0 7 1 4}$ \\
\hline
\end{tabular}

Source. Basic Education Statistics 2006 (MoEST)

Although the government through the Ministry of Education Science and Technology is funding the operations of religious schools and providing teachers, the reports from the two district education managers hinted that religious agencies have the power of appointing the school head teacher in their respective schools. Religious agencies appoint a dedicated member of the church, so that their doctrine is not misrepresented in the schools. This creates another leadership tension because the school leadership expected to be accountable to religious authorities as well as to the district education office authorities. This situation according to Ayee (1997: 39) leads to offices having divided loyalty. However, the head teachers interviewed indicated that they are responsible for teaching and learning, which means that they are accountability to the community in terms of the education of learners. In other words, they are accountable to provide education to the satisfaction of the learners and the community, and yet they are being hindered by lack of qualified staff and resources.

Since the advent of multiparty democracy, more development agencies are supporting the districts as development partners in different sectors. The district education manager acknowledged the roles played in capacity building by who?, which has helped participation during deliberation and decision making regarding development activities. However, the district education manager pointed the challenge which comes with the agencies. It is reported that agencies only address issues and activities that are related to their programs. In a situation where the agencies are few, many important issues are left unattended. The district leadership faces the challenge of ensuring that all development activities in the district align with the district and national agenda and not the agencies agendas.

\subsection{Understanding of decentralization}

Planning, implementation and monitoring of the decentralisation process were the responsibilities of the department of planning. The director of planning described the principles and practices behind decentralisation quite well. The director of planning was well informed when asked with regards to the purpose and origin of decentralisation, he said:

Decentralisation is there to provide the lower levels with authority. It was initiated specifically with the aim of empowering the district education office to implement issues without seeking approval from the parent Ministry. Decentralisation was adopted in the Ministry of Education, Science and Technology as a directive from the Malawi 
National Decentralisation Policy where all government departments were mandated to take on board decentralisation in their operational plans. It was a question of looking at what the Malawi National Decentralisation Policy is recommending and finding how to fit into the policy.

From the excerpt above it implies that the Ministry of Education, Science and Technology adopted and implemented education decentralisation as a way of empowering district education offices to implement the provisions of their mandate without seeking approval of higher offices on some matters. It can also be deduced that the implementation of decentralisation in education was a directive. The calls for efficiency which were stipulated in the decentralisation policy document were surprisingly not mentioned by the director of planning. Since implementation of the policy on decentralization appears to be in the form of a directive, some of its provisions were not properly internalised. For example, it had been observed that the procedure for achieving efficacy is not defined and whether community participation is linked to issues of efficacy in education is another matter.

\subsection{Reasons for decentralization}

On the reason behind education decentralisation, the views of the district education manager are encapsulated in the excerpt below:

I believe when power is close to where the work is done, the services are more effectively done, there are no delays in asking for approval and consultation and work is done more effectively as the district has the responsibility of being accountable when it fails.

Based on district education perspective, decentralisation appears to be an answer to the problem which has been affecting operations at the district level. It can be inferred that the manager is of the view that the main education activities are done at the district level and not at school as per structure. The manager was also sure of the effective operation of the district education office after decentralization. He said,

The district is where education decisions in the district are supposed to come from. Decentralisation makes the district education office responsible and accountable for the activities in the district.

Furthermore, the district education manager said that the district education office is strategically positioned to make education decisions in the district and the decentralisation will bring a feeling of responsibility and the office will be accountable for the decisions it makes.

On the reason to devolve authority to the district education office level and not to the other education structures below the district education office, the director of planning had this to say:

The Ministry of Education, Science and Technology structures go as far as primary schools, but this decentralisation was to be implemented in liaison with the Ministry of Local Government and Rural Development, as the pioneers of the whole exercise which has structures up to the district assembly. Ideally it would have been preferable that the education decentralisation activities had gone as far as schools, but one must bear in mind the practicality of Malawi in terms of funds and capacity and I do not see that as a realistic assumption.

Thus, the Ministry of Education, Science and Technology recognised that the structure of the ministry goes down to the school level. However, it is pointing at the structure of local government which end at the district assembly as the reason for not getting down to the school level. Furthermore, the director of planning is pointing at the capacity and structures at the school level. This is an assumption because the structure and capacity at school level has never been tried to verify the deficiencies. Therefore, since decentralisation was initiated by Ministry of Local Government and Rural Development, it means all activities were to be approved by the office of the Chief Executive officer in the District Assembly office. This is the first gate keeper for all activities coming to the district. And the structure for ministry of local government is up to district level. The district education office becomes the second gatekeeper for the education process, as they translate and interpret the state policies as well as implement decentralisation before activities reach the school. From what the district manager said above, the decentralisation of education is supposed to end at the district education

office. The district education office is ready to take the responsibility and become accountable for their decision. However, the decisions to decentralise education down to the district level was reached taking cognizance of the structure of education and where the final point of decentralisation was supposed to be. This raises the question, is decentralisation of education complete after stopping at district level.

\subsection{The role of the district office}

The role of the district during decentralization is encapsulated in the words of the district education manager as follows: 
The biggest thing is funding which has been devolved to the district office. We are funded according to our budget requirements and we are able to sit down and see what exactly we should do with the money to achieve our plans.

It is evident that the district education office controls the funds for its operations and it was responsible and accountable for its judicious expenditure in pursuit of the spirit and letter of decentralization as the manager insinuated. From the discussion with him, there were suggestions that the funding is full at this time than before and this will enable the district to achieve its plans which were not possible previousily. This implies that by adding funding to the district operation translates into successful decentralisation at district level. Another question still remains unanswered: has decentralisation reached the last point of the structure?

\subsection{Responsibilities which have not been devolved to the district level}

Regarding the other responsibilities which have not been devolved to the district education office, the district education manager said:

The district education office has no powers over curriculum content and the nature of the curriculum. The district education office has no powers on most issues related to teachers such as teacher disciplinary action, teacher recruitment, and teacher promotion and teacher remuneration. The district also has no power over supplies of resources.

The district education manager (EA) showed concerns that these functions which are not decentralised affect the district education managers' service delivery, such as teachers' welfare and other teacher related issues which require immediate attention to motivate them to teach. In the current arrangement, district education managers cannot discipline a teacher. This is a frustrating situation for the district education manager and represents a major problem in the decentralization milieu.

It is unpalatable and awkward that on one hand, the district education manager is supposed to provide schools with resources but on the other hand, he has no authority over acquisition of such resources. This situation makes work difficult because the district education manager is denied the responsibility to supply what districts regard as key school priority needs to ensure quality education. It can be argued that those devolving the authority are not in a position to appreciate the responsibilities which are appropriate and conducive to devolve functions for effective implementation. li is evident that those who work at the district level were not fully consulted about what was to be devolved to them.

Education departments were conscious of the need to maintain equal standards. However, they found it difficult to implement them when decentralisation is devolved to the school level. Yet it is on record that, districts had no time to prepare themselves by putting appropriate structures in place and build capacity for securing and monitoring standards hence and there was a lack of the pre-requisite capabilities such as knowledge and experience to oversee the decentralisation process at district level. Hence, this article argues that education decentralisation is incomplete under such circumstances.

\subsection{Leadership in the process of decentralization}

The literature agrees that quality leadership is a major ingredient for education effectiveness and improvement because leaders are central to the decision making process and are key players in such transformation initiatives (Davidoff and Lazarus 2002: 167). Leadership in this study is understood as those exercising authority, taking decisions, as well as directing and coordinating tasks relevant to the institutional goals. In this case, district and school leadership, all have authority to make decisions but leadership at school is undermined during decentralisation because it is more administrative than academic. As such, the issue of education efficiency/efficacy needs to be well defined. Implementation of decentralisation is often being challenged because of the failure of the system to support and promote the success of the decentralisation implementation process. This shows that, if the right leadership can be given room to exercise their authority, they will be able to plan accordingly in line with the imperatives of decentralization.

At the moment, the district office accounts by preparing and submitting monthly reports to the district assembly and Ministry of Education, Science and Technology. But there is no indication as to whether the reporting is for accountability requirements or for justifying the following month's government subvention. So there is a need to have a reporting system from districts that is specifically designed for accountability purposes. Stakeholders' attitude towards education decentralisation has been positive as they have been motivated by the willingness of districts to cooperate and allow donor support to flow.

This study found out that the district education office has the powers to develop plans and is responsible for the implementation of decentralisation activities in the sector. So it has to be accountable for the use of these powers. But there is no specific mechanism in place for evaluating the district leadership performance and for making it accountable 
for what it does. Given the current shortage of staff and resources, district leadership will use this as an excuse for not being able to deliver as expected.

\section{Discussion}

In the Ministry of Education, Science and Technology; the director of planning, district education managers, primary school advisors and head teachers, all have some formal authority to exercise by virtue of their positions. The decisions they make affect peoples' lives and create either a positive or negative climate which affects the education system as a whole and the community in general. Knowingly or unknowingly, they project a certain philosophy and vision which propels or hinders the education practice.

The appointment of a dedicated member of the church by religious agencies so that their doctrine is not misrepresented in the schools brings tension in the leadership allocation because the criteria for choosing leadership in education are competence and quality-based rather than church participation. Basing on the number of schools belonging to the religious organisations, it clearly shows that the primary school leadership is influenced by religious agencies. The lack of sufficient resources is a challenge for schools because they are supposed to develop alternative strategies to compensate for shortages in resources.

The execution of the roles and responsibilities of education officials are being impeded by lack of a common and shared understanding of what decentralisation is about in some quarters. There are added and duplicated responsibilities from the evidence given by the respondents. There is a need to create a network of partnerships between different stakeholders in order to link different capacities and to equip officials to handle new responsibilities or commitments to improve the education practice in Malawi. As such, capacity building programmes are needed to strengthen the level of competences of district staff for successful implementation of decentralisation.

The process of devolving responsibilities and functions to districts appears to be an ideal method of increasing participation in education decision making and development. The authority given to the district education office with its specific functions and responsibilities appears to have a positive effect on some of the district operations.

The interviews also showed that there was a lack of relevant information about decentralisation during the current implementation process suggesting that leadership was not well organized or prepared when the implementation process was instituted. However, since decentralisation goes in phases and steps, the delegation of responsibility has to be gradual in line with the experience acquired. Thus, the leadership is expected to plan concurrently for the challenge of capacity building of under qualified staff and resources supply.

The current education decentralisation process has delineated a channel of distribution and reporting of activities at different levels. The challenge remains the competences and authorities of the different levels of the education system to ensure that accountability is practiced such that it will not appear as a mere fulfillment of the legislative requirements. Advocates of decentralisation justify decentralisation on the grounds of increased efficiency, greater participation and responsiveness of government to citizens. Accountability is an intrinsic part of decentralization as it ensures that efficiency is pursued by the lower levels. This means that decentralisation needs some clarification about the goals to be achieved and the criteria to measure performance as it will make accountability clearer. The incompleteness and failure to have clear guidelines for decentralisation may contribute to a situation in which the stakeholders to whom authority is devolved are never held accountable. The current leadership dilemma is the divided loyalty the leaders are experiencing when executing their leadership roles and responsibilities due to the current decentralisation structure.

\section{Conclusion}

Leadership has to understand the process and take time to organize and develop the capacity for effective implementation. The lack of relevant information about decentralisation during the current implementation of decentralisation suggests that leadership was not well organized or prepared when the implementation process was instituted. Different departments and stages in the decentralisation process need to be regarded as distinct processes for effective planning and execution of education decentralization. Participation during decentralisation will only be possible at the point at which activities actually take place and as such advocacy is needed to bring awareness to stakeholders for effective implementation in which the allocation and provision of appropriate resources and training is a pre-requisite. Effort should be made to align the decentralisation structure so that leadership is committed and not to have divided loyalty. There is also a need to forge strong partnerships between different stakeholders in order to link different capacities and to equip officials to handle new responsibilities and commitments to improve education while capacity building programmes are needed to strengthen the level of competences of district staff for successful implementation of 
decentralization in the sector.

\section{References}

Anderson S, E (2003) The School District Role in Educational Change: A Review of the Literature: ICEC Working Paper No 2.

Ayee, J. R. A. (1997) Adjustment of Central Bodies to Decentralisation: The case of Ghanian bureaucracy: African Studies Review. 40(2)

Bray, M. (1985) Education and Decentralisation in Less Developed Countries: a comment on general trends, issues and problems with particular reference to Papua New Guinea. Comparative education. 21(2).

Bray, M. and Mukundan, M V. (2003) Management and Governance for EFA: Is decentralisation really the answer? www.hku.hk/cerc.

Chimombo, J.P.G. (2005) Decentralisation of Education Delivery: Lessons from SADC countries. Paper presented at the national conference of education 29th march to $1^{\text {st }}$ April 2005. Malawi Institute of Management.

Chisinga, B. (2005) District Assemblies in a Fix: the perils of the politics of capacity in the political and administrative reforms in Malawi. Development Southern Africa. 22(4).

Davidoff, S \& Lazarus S (2002) The Learning School: An Organisation Development Approach: $2^{\text {nd }}$ edition: Capt Town, Juta \& Co.

Davies, L., Harber, C., Dzimadzi, C. (2003). Educational Decentralisation in Malawi: a study of process. Compare. 33(2)

De Grauwe, A., Lugaz, C., Balde, C., Dougnon, D., Maustapha, M.\& Odushina, D. (2005) Does Decentralisation Lead to School Improvement? Findings and lessons from research in West-Africa. Journal of Education for International Development. 1(1)

Dyer, C., \& Rose, P. (2005). Decentralisation for Educational Development? An editorial introduction. Compare; 35(2)

Fullan M (2005) Turnaround Leadership: The Educational Forum. 69 (3)

Geo-Jaja, M. (2006). Educational Decentralisation, Public Spending and Social Justice in Nigeria. Review of Education. 52(3)

Government of Malawi (2006) National Basic Education Statistics: Government Press. Zomba.

Government of Malawi (1998) The Local Government Act, No. 42 of 1998, Government Press. Zomba

Government of Malawi, (1995) The Constitution of the Republic of Malawi, Act 7 of 1995. Government Press. Zomba

Government of Malawi (2002) Malawi Poverty Reduction Strategy Paper. Lilongwe, Government of Malawi

Government of Malawi (2001) Policy Investment Framework. Lilongwe, Government of Malawi.

Kashoti, D. (2007) Malawi budget "good, but democratic institutions sidelined" Afrol News, http://www.afrol.com/articles/19974.

Lane, J. \& Murray, M. (1985). The Significance of Decentralisation in Swedish Education. European Journal of Education, 20 (2-3)

McGinn, N. \& Welsh, T. (1999) Decentralisation of Education: Why, When, What and How? (Paris, IIEP).

Naidoo, J. (2003). Implementing Educational Decentralisation. Policy and Strategy Paper: second draft.

PIF (2001). Malawi Education Sector: Policy and Investment Framework. Ministry of Education, Science and Technology, Lilongwe on http://www.sdnp.org.mw/edu/new/min-education/whole.html

Rose, P. (2005) Privatization and Decentralisation of Schooling in Malawi: Default or Design? Compare 35(2)

Spillane, J P (2003) Educational Leadership: Educational Evaluation and Policy Analysis: 25 (4).

Tordoff, W. (1994) Decentralisation : Comparative Experience in Commonwealth Africa. The Journal of Modern African studies. 32 (4)

Work, R. (2002) Overview of Decentralisation Worldwide: A Stepping Stone to Improved Governance and Human Development. $2^{\text {nd }}$ international conference on decentralisation federalism: the future of decentralizing states. Manila, Philippines.

United Nation Development Program (UNDP) (2000). Decentralized Governance in Malawi: Lilongwe UNDP 